\title{
PANDEMIA VIRAL E PANDEMIA ECONÔMICA
}

Norbert Fenzl

Possui graduação em Geologia pela Universidade de Viena, (Áustria) (1971), doutorado em Hidrogeologia - Ciências Ambientais pela Universidade de Viena (1975) e pos-doutorado pela Universidade Tecnica de Viena (1993). Atualmente é pesquisador e professor Titular da Universidade Federal do Pará, Núcleo de Meio Ambiente (NUMA), Coordenador do Projeto GEF Amazonas - Gestão Integrada Recursos Hidriocos da Bacia Amazonica, Consultor do CORDIS (Community Research Development Information Service) da União Europeia. E-mail: nfenzl@gmail.com

\section{RESUMO}

O artigo trata de uma análise sobre o contexto socioeconômico e político da pandemia Covid-19, fundamentado no delírio neoliberal globalizado, que destrói a resiliência dos países no enfrentamento de epidemias ou pandemias como aquela que estamos enfrentando agora. O desmantelamento da saúde pública, desemprego, desnutrição e fome não somente enfraquecem o sistema imunológico do indivíduo, mas também o que podemos chamar de sistema imunológico da nação. Portanto, não adianta tratar a pandemia como uma simples questão de saúde público e esperar a vacina como o salvador da pátria. Sem abordagem sistêmica, percebendo a verdadeira complexidade do assunto que é muito mais abrangente da questão virológica, não sermos capazes de tirar nenhuma lição sustentável desta pandemia.

PALAVRAS-CHAVE: Corona Vírus. Neoliberalismo. Imunidade Social.

\section{VIRAL PANDEMIC AND ECONOMIC PANDEMIC}

\begin{abstract}
The article deals with an analysis of the socio-economic and political context of the Cornoa-19 pandemic, based on the globalized neoliberal delusion, which destroys the resilience of countries in facing epidemics or pandemics like the one we are facing now. The dismantling of public health, unemployment, malnutrition and hunger not only weakens the individual's immune system, but also what we can call the immune system society. Therefore, there is no point in treating the pandemic as a simple public health issue and waiting for the vaccine
\end{abstract}


as the savior of the country. Without a systemic approach, realizing the true complexity of the subject that is much broader than the virological issue, we will not be able to draw any sustainable lessons from this pandemic.

KEYWORDS: Corona Virus. Neoliberalism. Social Immunity.

\section{INTRODUÇÃO}

O filósofo e linguista estadunidense Noam Chomsky, em conversa com o filósofo e co-fundador do DiEM25 - Democracy in Europe - Srecko Horvat, foi contundente ao afirmar: Devemos pensar sobre a origem desta crise, por quê há uma crise do Corona-Vírus? É uma falha colossal do mercado e nos leva direto a essência dos mercados exacerbados pelo neoliberalismo selvagem, a intensificação neoliberal, os problemas socioeconômicos decorrentes.

Vivemos numa época de grandes transformações e incertezas em todas as áreas e campos, tanto no plano individual, familiar, como do país e da humanidade. Quais os caminhos da economia globalizada e da dominação hegemônica do capital financeiro? Essas perguntas, em princípio, não são novas, especialmente depois da grande crise financeira de 2008 cujas consequências e desdobramentos dramáticos ainda estão por vir.

Entretanto, essas questões se colocam hoje num contexto muito mais explosivo em termos geopolíticos, econômicos e sociais. A pandemia de COVID-19 acelerou dramaticamente todas as contradições e antagonismos acumulados nesta fase da evolução do capitalismo global.

A pandemia criou um pânico em todos os países do mundo e sabemos que em situações de pânico, muitas coisas podem dar erradas e medidas podem ser tomadas cujas consequências em curto, médio ou longo prazo ainda estamos longe de compreender, mesmo que os primeiros sinais já sejam bastante preocupantes: a massiva quebra de pequenas e média empresas, mesmo grandes corporações internacionais e, especialmente, aquelas ligadas ao transporte aéreo, marítimo, turismo e serviços já estão quebrando com poucas perspectivas de recuperação. Como consequência direta, observamos uma verdadeira explosão do desemprego em todos os países do mundo.

Somente a título de ilustração uma tabela publicada pelo FMI que ilustra a situação econômica global. Por mais cautelosos que precisamos ser com dados do FMI, uma coisa é óbvia: um desastre econômico de proporção global é anunciado e parece que a única potência que se levantará das cinzas será a China. 


\begin{tabular}{|c|c|c|}
\hline \multicolumn{3}{|c|}{ Previsão econômica do FMI para 2020 (FMI) } \\
\hline Países & $\begin{array}{c}\text { Crescimento } \\
\text { econômico } \\
\text { em 2020 }\end{array}$ & $\begin{array}{c}\text { Crescimento } \\
\text { econômico } \\
\text { esperado em 2021 }\end{array}$ \\
\hline EUA & $-\mathbf{8 . 0}$ & $\mathbf{4 . 5}$ \\
\hline Alemanha & -7.8 & 5.4 \\
\hline França & -12.5 & 7.3 \\
\hline Itália & -12.8 & 6.3 \\
\hline Espanha & -12.8 & 6.3 \\
\hline Japão & -5.8 & 2.4 \\
\hline Grã-Bretanha & -10.2 & 6.3 \\
\hline Canada & -8.4 & 4.9 \\
\hline China & $\mathbf{1 . 0}$ & $\mathbf{8 . 2}$ \\
\hline Índia & -4.5 & 6.0 \\
\hline Brasil & -9.1 & 3.6 \\
\hline
\end{tabular}

\section{A PANDEMIA E A RESILIÊNCIA DO SISTEMA ECONÔMICO}

É importante ressaltar de antemão que neste trabalho compreende-se a infância como uma categoria histórica e social (ÀRIES, 1981; KRAMER, 1982). Segundo Kramer (1981) o conceito de infância não existiu sempre e da mesma maneira, ela aparece com a sociedade capitalista, urbano-industrial, na medida em que modificam a inserção e o papel social da criança na comunidade. Dessa forma se na sociedade Feudal, a criança exercia um papel.

Qual é o papel da pandemia no contexto da crise econômica global que ficou evidente em 2008 e que se agravou paulatinamente desde então? Muitos economistas estavam prevendo um colapso do sistema financeiro bem antes da pandemia porque nenhuma medida efetiva foi tomada pelos governos do mundo para controlar a gigantesca especulação financeira que causo a crise de 2008.

Vale a pena reproduzir as palavras do economista alemão Ernst Wolff, que disse a respeito ${ }^{1}$ :

Pela primeira vez em sua história, a economia global foi deliberadamente quase completamente paralisada. Isso causou danos, cujas consequências nas próximas semanas e meses excederão tudo o que a humanidade já experimentou em tempos de paz..., mas isso parece ser apenas o começo. Há sinais crescentes de que não vamos corrigir esse rumo, mas sim continuar e até mesmo aprofundá-lo. Como no passado, mesmo com surtos de doenças igualmente perigosas, não havia

\footnotetext{
${ }^{1}$ https://kenfm.de/the-great-reset-was-steckt-dahinter-von-ernst-wolff/

Complexitas - Rev. Fil. Tem., Belém, v. 5, n. 1 , p. 47-55, jan./dec. 2020 - ISSN: 2525-4154
} 
medidas tão extensas e radicais para contê-los como no caso da COVID-19, levanta-se a suspeita de que a alegada preocupação com a saúde da população poderia ser outra... A elite financeira e política mundial, cujos principais representantes se reunirão sob o lema - The Great Reset - em janeiro de 2021 em Davos para o Fórum Econômico Mundial (WEF) declararam que o „Grande Reinício“ será o leitmotiv para o futuro da humanidade...E, de fato - um reinício abrangente é iminente e inevitável, por duas razões: por um lado, porque o setor financeiro global em sua forma atual não é mais capaz de funcionar no longo prazo e, por outro lado, porque a economia real global está enfrentando a maior reviravolta de sua história...Desde a crise financeira global de 2007/08, o sistema financeiro global tem sido mantido vivo apenas artificialmente pelos bancos centrais mundiais, nomeadamente reduzindo continuamente as taxas de juro básicas e criando dinheiro do nada.Por isso, os bancos centrais são obrigados a imprimir dinheiro sem lastro na economia real. A destruição de centenas de milhões de empregos em todo o mundo tem consequências fatais, porque essas pessoas falham como contribuintes, como consumidores e, portanto, como força motriz da economia. O dinheiro do helicóptero, que se torna necessário por causa dos milhões de desempregados e que só serve para aumentar a demanda, é apresentado ao grande público como a "renda básica incondicional". E a digitalização das pequenas e médias empresas é idealizada como um caminho para um futuro mais justo, embora isso nada mais é do que a subordinação destas empresas às plataformas da Internet, cujo poder de mercado atualmente cresce incomensuravelmente.A elite financeira, cerca de $0,001 \%$ da população mundial, está em processo de liderar o resto da humanidade para uma espécie de ditadura digital. Os efeitos do lockdown e as medidas adicionais tomadas para conter uma "segunda onda“ terão consequências sociais e econômicas tão devastadoras que muitos milhões de pessoas entrarão em conflito crescente com o sistema econômico e político existente e é justamente esse conflito que oferece a oportunidade única de educar um grande número de pessoas até então desavisadas que a Grande Restauração nada mais é do que uma tentativa de manter vivo um sistema que historicamente já está agonizando.

Com isso, para entender o papel da pandemia de COVID-19 no atual contexto histórico é necessário olhar para a economia global de forma sistêmica e evitar analisar o vírus como um inimigo "externo" que ataca a humanidade de maneira imprevista e somente pode ser vencido através de uma vacina salvadora da pátria e da humanidade.

Como sempre, o problema é muito mais sério porque o número das vítimas e o impacto econômico da pandemia são diretamente ligados à resiliência do sistema socioeconômico. Em 
outras palavras, uma sociedade, tal como um corpo humano precisa de um sistema imunológico que lhe confere a resiliência necessária para superar graves crises como a pandemia atual. Alguns conceitos:

- Pandemia (do grego antigo pan abrangente, e dēmos pessoas) refere-se à propagação de uma doença geralmente infecciosa, entre países e continentes, enquanto uma epidemia, é a propagação de uma infecção de maneira restrita regionalmente. Por exemplo, no que diz respeito à gripe, a Organização Mundial da Saúde (OMS) modificou as diretrizes para a gestão de risco em maio de 2017. O aspecto curioso nesta modificação é o fato que a decisão da transição de uma epidemia para uma pandemia deve ser realizada pelo Diretor-Geral da OMS.

- Sistema imunológico protege o nosso corpo, evitando que substâncias estranhas afetem negativamente nossa saúde. É um sistema complexo que envolve uma série de células e órgãos que formam juntos uma grande barreira de proteção. A imunidade que pode ser inata (os indivíduos já nascem com estes mecanismos de defesa) e/ou adquirida, quando o indivíduo a desenvolve durante sua vida. Em analogia podemos dizer que numa sociedade, instituições eficientes, transparentes e comprometidas com uma constituição democrática, serão capazes de formar uma barreira de proteção contra todo tipo de perigos tanto internos como externos.

- Resiliência é um conceito que é usado tanto para pessoas, coletivos, ecossistemas ou para sistemas complexos de um modo geral. Assim, podemos definir resiliência como (i) a capacidade das pessoas de dominar e superar crises com risco de morte, usando recursos próprios e socialmente adquiridos ou (ii) a capacidade de ecossistemas e sistemas complexos em geral de manter a estabilidade da organização básica em face de distúrbios externos ou internos.

Sistemas resilientes conseguem sair mais fortes de uma situação de crise. O mesmo vale para uma sociedade quando ela tem a capacidade de aprender e incorporar lições históricas. Num discurso para o Itamaraty o ex-presidente Lula mencionou os perigos daquilo que ele chamou de "consciência de vira lata". Essa falta de autoconfiança e autoestima da sociedade brasileira estimula o pessimismo coletivo e é um dos principais entraves para a gerar a resiliência social indispensável para enfrentar uma crise. 
Assim, o primeiro fator fundamental é a autoconfiança e autoestima da população, que gera o otimismo necessário e o abandono do papel de vítima. A sociedade precisa perceber que as crises, por piores que pareçam, são temporárias e dialéticas. Portanto, sempre abrem também perspectivas de mudanças, construção de novas redes e alianças sociais e políticas e possibilidades de planejar e redesenhar o futuro.

O segundo fator de importância é a aceitação da crise. Somente se a crise for reconhecida e encarada no seu nível de complexidade, ela poderá ser enfrentada. Percebemos imediatamente a analogia com a atualidade. A sociedade que enfrenta a pandemia da COVID19 requer um "sistema imunológico" e ter resiliência para poder superar a crise. Assim, é preciso fazer uma avaliação criteriosa do nosso nível de resiliência, tanto da economia global como da situação específica do Brasil.

É importante frisar que ainda subestimamos consideravelmente o grau de globalização dos nossos países e o nível de integração e interdependência das economias nacionais. Se antigamente cada país se entendia ser um navio, com seu próprio capitão, navegando junto com todos os outros num mar comum, hoje podemos dizer que os países ocupam os diversos camarotes, do mesmo transatlântico. Claro, alguns países estão hospedados na $1^{\mathrm{a}}$ classe e têm acesso ao comando do navio. Muitos outros ocupam classes inferiores, com uma participação insignificante nas decisões sobre os rumos do transatlântico. Por isso, é fundamental abordar o problema da pandemia no contexto do conjunto dos problemas que a "sociedade global" enfrenta hoje. Por mais que cada país enfrente problemas específicos, as causas raízes são basicamente as mesmas.

\section{COMO AVALIAR O NÍVEL DE RESILIÊNCIA E O "SISTEMA IMUNOLÓGICO" DE CADA SOCIEDADE?}

Para verificar a capacidade de um país de enfrentar problemas que ameaçam a população e a integridade da sociedade, vejamos inicialmente quais os principais problemas da humanidade - ou seja - da sociedade global. De acordo com o Borgen Project - Biggest World Issues $^{2}$ o mundo sofre atualmente de 10 problemas, considerados essenciais. Pessoalmente, acho que ainda falta o problema global do acesso à água potável e ao saneamento básico que atinge em torno de 2 bilhões de pessoas no mundo.

\footnotetext{
${ }^{2}$ https://borgenproject.org/world-issues/ 
1. Desnutrição e fome: De acordo com a Food Aid Foundation, 795 milhões de pessoas no mundo não estão recebendo a quantidade adequada de nutrientes. Além disso, a fome é o principal problema de saúde entre crianças e adultos, causando aproximadamente 45 por cento das mortes de crianças.

2. AIDS: HIV / AIDS é uma epidemia, na qual mais de 36,7 milhões de pessoas convivem com a doença. Atualmente, cerca de 2,1 milhões de crianças têm a doença e, só em 2016, um milhão de pessoas morreram.

3. Malária: Aproximadamente 3,2 bilhões de pessoas são vulneráveis à malária - isso é metade da população mundial. As crianças pequenas são as mais suscetíveis e cerca de 445.000 pessoas morreram de malária em 2016.

4. Poluição do Ar: A poluição do ar é um problema ambiental global que causa problemas de saúde e escassez de alimentos. Os poluentes prejudicam os suprimentos de alimentos e as plantações, o que cria ainda mais problemas de desnutrição e fome. Os poluentes também prejudicam diretamente a vida humana. De acordo com a Conserve Energy Future, 65 por cento das mortes na Ásia e 25 por cento das mortes na Índia são devido à poluição do ar.

5. Falta de direitos humanos: os sistemas políticos prejudicam os direitos humanos e as liberdades inerentes a cada indivíduo, independentemente de sua demografia, religião, cultura, gênero, raça. Em 2014, a Anistia Internacional registrou que mais de um terço dos governos aprisionou seus cidadãos que estavam exercendo seus direitos.

6. Falta de educação: O direito à educação não é garantido em muitos países devido a questões como desigualdade entre diferentes etnias ou classes, violência e pobreza. 72 milhões de crianças não estudam e cerca de 759 milhões de adultos são analfabetos.

7. Desigualdade de gênero: devido à desigualdade de gênero, a educação e as oportunidades econômicas são inacessíveis para muitas mulheres de todas as origens. Cerca de 150 países têm leis que discriminam os direitos das mulheres. Sub-representadas em órgãos governamentais, as mulheres ocupam apenas uma média de $23 \%$ nos assentos parlamentares.

8. Conflitos e guerras: muitos conflitos ativos no mundo de hoje têm efeitos devastadores para os cidadãos que vivem em áreas atingidas pelas guerras. O número total de vítimas da Guerra no Iraque chegou a cerca de 800.000 pessoas. Líbia, Somália, Iêmen e Síria já somaram ao redor de 765.000 pessoas, e uma em cada quatro crianças é vítima da guerra.

9. Refugiados: O número de indivíduos que foi forçado a deixar suas casas disparou drasticamente nos últimos anos. O Centro de Monitoramento de Deslocamento Interno (iDMC) 
relatou que 31,1 milhões de pessoas fugiram dos seus países em 2016. O deslocamento se deve à miséria e fome, desastres naturais e guerras. $\mathrm{O}$ número de indivíduos deslocados aumentou para aproximadamente 60 milhões devido a conflitos armados no Oriente Médio, especialmente Líbia, Afeganistão e Síria, que conta com cerca de 11 milhões de refugiados, incluindo idosos e crianças pequenas.

10. Pobreza global: A pobreza é uma questão mundial abrangente que afeta, entre outros, a infraestrutura, saúde, educação e direitos humanos. Aproximadamente um bilhão de crianças vivem na pobreza e $80 \%$ das pessoas vivem com menos de US \$ 10 por dia. Além disso, a cada 10 segundos, cidadãos em todo o mundo morrem devido a problemas relacionados à pobreza. $\mathrm{E}$ a diferença entre a disparidade econômica e de renda entre os países está aumentando.

Os dados demostram claramente o sistema econômico global se encontra num estado lamentável. Da mesma forma como uma pessoa mal- ou desnutrida, debilitada fisicamente com diversos problemas existenciais, estresse e doente, tem um sistema imunológico debilitado e será a primeira a morrer numa pandemia, uma sociedade enferma tem baixa capacidade de autodefesa ou imunidade em relação à uma ameaça do tipo COVID-19.

No caso específico do Brasil, basta um clique no Google para saber que o país sofre de gravíssimos problemas, entre outros, de saúde pública, saneamento, miséria, desemprego. Ou seja, que o sistema imunológico do país é extremamente debilitado.

Lembrando as palavras iniciais do Noam Chomsky, o neoliberalismo selvagem e um governo completamente incompetente enfraquecem o país de tal maneira que não precisamos de nenhuma bola de cristal para entender por que a COVID-19 atinge com violência países como Brasil.

\section{QUAIS AS LIÇÕES QUE DEVERÍAMOS TIRAR DA PANDEMIA?}

Primeiro: não é o vírus que é a verdadeira ameaça para a sociedade brasileira; é a própria estrutura política, social e econômica que é profundamente corrompida e deteriorada ao ponto que qualquer que seja a ameaça, os impactos serão graves e especialmente dolorosos para os milhões de cidadãos desprotegidos. Portanto, é uma ilusão achar que uma simples vacina vai nos salvar do vírus e depois o problema da pandemia estaria resolvido.

Segundo: A pandemia mostra com maior clareza as contradições, problemas e deficiências do "sistema imunológico" da sociedade e permite assim o surgimento de um novo nível de consciência coletiva e consciência de classe. Nestas condições, novas alianças políticas e 
sociais são possíveis e novas soluções podem surgir.

Terceiro: Lembramos que a crise que vivemos atualmente é qualitativamente diferente das crises cíclicas clássicas do capitalismo do passado. Do ponto de vista sistêmico, isto significa que estamos enfrentando um ponto de bifurcação. Segundo F. Capra, um ponto de bifurcação é um limiar no qual o sistema pode se desintegrar ou então imergir em novos estados de organização. A maneira como o sistema reage nesse ponto crítico depende da história anterior do sistema.

Qual é o significado do ponto de bifurcação para a situação atual do Brasil? Dependendo da lição que seremos capazes de tirar do caminho que nos levou ao ponto de instabilidade e caos atual, tomaremos um dos caminhos disponíveis depois da pandemia. E não há nenhuma garantia que o caminho escolhido nos levará para uma saída positiva da crise!

Em outras palavras, no limiar de uma mudança tão profunda, todos os setores saudáveis da sociedade, intelectuais e lideranças progressistas, têm uma responsabilidade sem precedentes. Para o bem desse povo sofrido, esperamos que todos estejam à altura do desafio.

\section{REFERÊNCIAS BIBLIOGRÁFICAS}

ARIÈS, Philippe. História social da criança e da família. Trad. Dora Flaksman. $2^{\mathrm{a}}$ edição. Rio de Janeiro:

Zahar Editores, 1981. p. 279

FUNDAÇÃO ABRINQ. Cenário da Infância e Adolescência no Brasil. 2019.

Rio de Janeiro. Achiamé, 1982.

KRAMER, Sônia. A política da préLAMARÃO, Maria Luiza Nobre. Caderno Pedagógico: metodologias de trabalho com crianças e adolescentes institucionalizados. Belém. PA. UNICEF, 2007.

NOGUEIRA, M. D. P. Políticas de Extensão Universitária Brasileira. Belo escola no Brasil: a arte do disfarce. Horizonte: Editora UFMG, 2005.

FENZL, N. Pandemia Viral e Pandemia Econômica. Complexitas - Rev. Fil. Tem. Belém, v. 5, n. 1, p. 47-55, jan./dec. 2020. Disponível em: http://www.periodicos.ufpa.br/index.php/complexitas/article/view/9488>. Acesso em: $01 \mathrm{de}$ novembro de 2020. 